\title{
$O$ reconhecimento e as garantias constitucionais dos direitos fundamentais
}

\begin{abstract}
Anderson Cavalcante Lobato*
Sumário: I.- O reconhecimento jurídico-constitucional dos direitos fundamentais; A/ A constitucionalização dos direitos fundamentais; 1.A finalidade do Estado e a evolução dos direitos do homem; 2.A definição dos direitos fundamentais; B/ As gerações dos direitos fundamentais; C/ Os direitos fundamentais reconhecidos pela Constituição Federal de 1988; II.- As garantias jurídicas dos direitos fundamentais; A/ A garantia de aplicabilidade imediata dos direitos fundamentais; $\mathrm{B} / \mathrm{Os}$ limites materiais impostos ao processo de reforma constitucional; $\mathrm{C} / \mathrm{As}$ restrições impostas à decretação do estado de exceção constitucional; III.- As garantias jurisdicionais: as ações constitucionais de proteção dos direitos fundamentais; A/ As ações constitucionais de proteção dos direitos individuais e coletivos; B/ As ações constitucionais de proteção dos direitos sociais, econômicos e culturais.
\end{abstract}

A problemática dos direitos fundamentais aparece inicialmente no momento das lutas contra o Estado absolutista monárquico. O primeiro documento que procurou de algum modo restringir os poderes do Monarca surgiu na Inglaterra de 1.215 com a Magna Carta outorgada por João Sem-terra. Séculos mais tarde, nas terras do novo mundo, foi proclamada a Declaração de Direitos do Estado de Virgínia, pouco antes da Declaração de Independência dos Estado Unidos da América, no ano de 1.776. No entanto, as declarações de direitos somente alcançaram uma dimensão universal com a Declaração de Direitos do Homem e do Cidadão, proclamada pelos revolucionários vitoriosos, na França de 1.789.

As declarações de direitos inauguraram uma nova fase nas relações entre governantes e governądos. Se do ponto de vista tradicional ao homem era atribuído tão-somente obrigações, com as Declarações de Direitos, o homem, visto como indivíduo, adquire direitos, cabendo ao governante o

* Pesquisador Recém-Doutor do CNPq junto ao Curso de Pós-Graduação em Direito da UFPR; Doutor em Direito pela Universidade de Ciências Sociais de Toulouse - França.

R. Fac. Direito, Curitiba, a.28, n.28, 1994/95, p.109-137 
dever de garanti-los. Essa inversão radical nas relações entre soberanos e súditos, dá origem ao Estado moderno que evoluirá em conformidade com a afirmação e o reconhecimento de novos direitos do homem. ${ }^{1}$

Fato é que os direitos do homem são na verdade direitos históricos, reconhecidos à medida que as condições da vida em sociedade se transformam; não são pois fruto da natureza, mas sim da civilização. ${ }^{2}$ Das declarações de direitos até chegarmos à afirmação dos direitos fundamentais, que adquirem valor jurídico-constitucional, os direitos inerentes à pessoa humana passaram por um longo processo de reconhecimento e constitucionalização. A problemática dos direitos do homem hoje não seria tanto a busca de justificação teórica. mas sim de garantir-lhes proteção jurídica e jurisdicional. Os países ocidentais, em sua grande maioria, trazem nas suas Constituições nacionais o reconhecimento do valor jurídico-constitucional dos direitos do homem, porém quando se trata de garantir-lhes efetividade e concretização, os mecanismos jurídicos e jurisdicionais são ainda precários e de difícil acesso. Para melhor compreendermos a proteção dos direitos fundamentais, será necessário cuidarmos primeiramente do processo de seu reconhecimento jurídico-constitucional, para assim identificarmos claramente os direitos tutelados (I). Somente então, estaremos em posição de analisar as garantias jurídicas (II) e jurisdicionais (III) de proteção dos direitos fundamentais.

\section{I.- O reconhecimento jurídico-constitucional dos direitos fundamentais}

As declarações de direitos da primeira fase do constitucionalismo liberal adquiriram um valor jurídico extremamente reduzido. É certo que cuidavam da afirmação de princípios fundamentais que deveriam ser reconhecidos e garantidos pela ordem constitucional, entretanto, o fato de não estarem inseridos no próprio texto da Constituição, dificultava sobremaneira o processo de garantia, seja jurídica, seja jurisdicional.

1 Norberto Bobbio, A era dos direitos, tradução de Carlos Nelson Coutinho, Rio de Janeiro, Editora Campus, 1992, p. 100.

2 Norberto Bobbio, A era.... op. cit., p. 32. 
Vejamos pois alguns aspectos deste longo processo de constitucionalização dos direitos (A), passando pela sua classificação em gerações (B). para então analisar particularmente aqueles direitos reconhecidos pela Constituição brasileira de 1988 (C).

\section{A/ A constitucionalização dos direitos fundamentais}

O processo de constitucionalização dos direitos do homem seguiu a mudança de concepção do Estado de Direito que, partindo de uma compreensão estritamente liberal e individualista do homem. passou a compreendê-lo a partir de seu contexto social, econômico e cultural. Trata-se justamente de uma mudança radical do papel do Estado na vida em sociedade, que além de garantir os direitos de liberdade, passa a ser compreendido enquanto promotor do bem-estar social, permitindo a necessária correção das desigualdades econômicas e sociais.

Pouco a pouco os direitos do homem adquirem um valor fundamental para a própria compreensão do Estado de Direito. De fato, o Estado de Direito representando o Estado constitucional submisso às regras do Direito, por si só não mais podia expressar a idéia de direito inerente no seio da sociedade, que segundo Georges Burdeau, permitiria o nascimento do Estado através do processo de institucionalização do poder político, onde "as vontades dos governantes só têm valor jurídico quando atribuídas ao Estado; quer dizer quando elas estão conformes à idéia de obra a qual o Poder institucionalizado é a energia criadora". ${ }^{3}$ Seria pois necessário identificarmos claramente a finalidade do Estado que passa a ser considerada enquanto um elemento constitutivo do Estado moderno. ${ }^{4}$

É importante ressaltar desde logo a estreita ligação que existe entre a passagem do Estado liberal de direito ao Estado social de direito e a evolução dos direitos do homem (1.), para então procurar uma definição

3 Georges Burdeau. L'État, Paris, Seuil, 1970, p. 47.

4 Dalmo de Abreu Dallari, Elementos de Teoria (ieral do Estado, São Paulo, Saraiva. 1985 , p. 90 e ss.

R. Fac. Direito, Curitiba, a.28, n.28, 1994/95, p.109-137 
dos direitos fundamentais inseridos no próprio texto das constituições dos Estados (2.).

\section{A finalidade do Estado e a evolução dos direitos do homem}

Assim como a problemática dos direitos do homem, a idéia de Estado de Direito surgiu primeiramente na Europa do século XVIII durante a luta contra o Estado absolutista. ${ }^{5}$ A sua evolução histórica começa com a afirmação do Estado de Polícia, que assumia a função de oferecer segurança e promover o desenvolvimento do Estado, sempre através de medidas de intervenção administrativa na vida das pessoas. Logo se percebeu que freqüentemente a administração se colocava acima das leis. De fato, no Estado de Polícia se entendia que os governos e a administração poderiam, discricionariamente e com uma grande liberdade de decisão, impor aos cidadãos todas as medidas necessárias para se atingir os fins perseguidos, sempre com fundamento no interesse público. ${ }^{6}$ Neste sentido, o Estado de Polícia se identificava com o Estado absolutista na medida que, embora sujeito a uma ordem jurídica, esta não era capaz de estabelecer limites e proteger os cidadãos em face do poder político estatal.

O Estado de Direito surgiu então com o objetivo de submeter o poder político às regras do direito. De modo que a administração encontraria no direito os limites à ação do Estado em face dos direitos reservados aos cidadãos. Portanto, o Estado de Direito se caracterizaria pela existência de: (a) uma ordem jurídica definindo os direitos do cidadão e limitando o poder político do Estado; e igualmente, (b) um controle judicial da aplicação das regras de direito. Este controle seria pois indispensável para a realização do Estado de Direito e poderia ser exercido por juízes ordinários ou por juízes especiais, como por exemplo os juízes administrativos.

5 José Luiz Quadros de Magalhães, "Direitos humanos: evolução histórica", Revista Brasileira de Estudos Politicos, UFMG, 1992(74/7, ), p. 109.

6 Jacques Chevallier, "L'État de droit", Revue du Droit Public et de la Science Politique en France et à l'étranger, Paris, LGDJ, 1988, p. 329; Ver ainda: Marie-Joèlle Redor, De l'Etat légal à l'État de droit. L'évolution des conceptions de la doctrine publiciste française (1879-1914), Paris, Economica/PUAM, 1992, p. 389. 
A necessidade do controle judicial da aplicação das regras de direito, conduziria à compreensão de uma ordem jurídica hierarquizada, tendo-se como princípio de base a supremacia da Constituição.

Particularmente interessante foi o exemplo francês, onde a evolução para o Estado de Direito passou por uma fase de afirmação da supremacia da Lei. Esta situação foi denominada de Estado Legal, onde somente a Lei teria a legitimidade popular necessária para impor limites ao poder político do Estado. ${ }^{7}$ Neste sentido, o Estado Legal, embora representando um progresso em relação ao Estado de Polícia, não poderia oferecer ao cidadão todas as garantias do Estado de Direito, posto que, de um lado, a ordem jurídica hierarquizada estava prejudicada em razão da impossibilidade de se impor às leis o respeito às regras constitucionais; por outro lado, e conseqüentemente, não se poderia pensar na existência do controle judicial da constitucionalidade das leis.

As duas exigências do Estado de Direito, embora essenciais à afirmação de um Estado não-absolutista, não foi suficiente para oferecer a idéia de direito subjacente ao Estado contemporâneo. Assim procurou-se introduzir um qualificativo, a saber: Estado liberal de direito, Estado social de direito e Estado democrático de direito.

A principal característica do Estado liberal é sem dúvida a busca constante pela não intervenção do Estado nas relações entre particulares. O Estado liberal é consequência direta da luta contra o Estado absolutista e deste modo procura limitar ou conter os poderes do Estado, ao mesmo tempo que procura proteger os indivíduos das possíveis ingerências da administração na vida privada.

A idéia de Estado de direito liberal traz consigo a somatória de dois princípios inerentes ao Estado de direito: (a) a separação de poderes, onde pela divisão ou separação das três funções essenciais do Estado, legislar, executar e julgar, poder-se-ia assegurar o controle da atividade de um poder político pelo outro de mesmo nível; (b) o reconhecimento dos direitos individuais, que seriam inseridos no texto constitucional e assim protegidos pelo controle da constituciónalidade das leis.

7 Jacques Chevallier, L'État..., op. cit., p. 333.

R. Fac. Direito, Curitiba, a.28, n.28, 1994/95, p.109-137 
A idéia de Estado social parte da constatação de que a não intervenção do Estado nas relações particulares teria trazido uma desigualdade entre os indivíduos. Os mais fortes economicamente, estariam sendo beneficiados em detrimento dos indivíduos menos favorecidos pelas relações econômicas.

Haveria pois necessidade de uma intervenção do Estado em favor dos mais fracos economicamente, que só seria legítima se regulada, limitada e controlada pelo direito.

Assim, no Estado de direito social se procurou primeiramente alargar a enumeração dos direitos individuais que estariam protegidos pela Constituição do Estado, concedendo-lhes por um lado, uma dimensão coletivista, social, econômica e cultural, e, por outro lado, afirmando-se a obrigação do Estado em oferecer os meios necessários para a sua concretização.

É flagrante, nos nossos dias, a oposição entre as concepções do Estado liberal e do Estado social de direito. No momento da reconstrução dos Estados destruídos pela segunda grande guerra na Europa, em razão dos movimentos totalitários que souberam canalizar as insatisfações individuais, advindas das desigualdades entre as pessoas, as novas Constituições optaram pela afirmação de um Estado Social de Direito. ${ }^{8}$

No entanto, recentemente, os anos setenta e oitenta, foram marcados pelos movimentos neoliberais que, pouco a pouco, procuraram reformar as constituições sociais e, sobretudo, interferir no momento de elaboração das novas constituições que surgiram em razão da luta contra regimes autoritários, seja na Europa, seja na América Latina. O objetivo principal seria pois a desconstitucionalização, ou seja, a supressão no texto constitucional daquelas matérias, de ordem econômica e social, que segundo esta corrente doutrinária, estariam dificultando o natural desenvolvimento da sociedade.

Procurou-se então um compromisso entre as posições liberalizantes e socializantes do Estado. Este compromisso foi possível pela clara afirmação do princípio democrático, onde cada corrente poderia buscar, no

8 Paulo Bonavides, Do Estado Liberal ao Estado Social, Belo Horizonte, Del Rey, 1993, p. 48 . 
debate político interno, o apoio popular para a implantação de programas liberais ou sociais de governo.

A Constituição brasileira de 1988 adotou a expressão "Estado Democrático de Direito", onde se procurou ressaltar o princípio democrático que deve prevalecer sob toda a construção jurídica criada pelo novo texto constitucional.

De fato, quando a Constituição brasileira de 1988 afirma no seu artigo $1 .^{\circ}$ que a República Federativa do Brasil constitui-se em Estado democrático de direito, assume, na realidade, um compromisso entre as concepções liberal e social, do Estado de Direito. Assim, a concretização do Estado de Direito pressupõe a realização de certos princípios constitucionais, tais como o princípio da juridicidade, da constitucionalidade, da separação dos poderes, dos direitos fundamentais, e, no contexto do Estado democrático de direito, o princípio democrático.

\section{A definição dos direitos fundamentais}

É comum encontrarmos diversas expressões que buscam designar aqueles direitos inerentes à dignidade da pessoa humana e que estão por conseguinte, protegidos pela Constituição. Contudo, pode-se indicar desde logo certas particularidades que serão de grande utilidade para a correta compreensão do significado jurídico-constitucional dos direitos fundamentais. ${ }^{10}$

De fato, por muito tempo utilizou-se a expressão direitos naturais para designar aqueles direitos inerentes à natureza do homem e à sua finalidade no mundo. Esta expressão estava sem dúvida fortemente vinculada à corrente filosófica do jusnaturalismo e procurava assim conceder um caráter universal aos direitos então reconhecidos pelas declarações de direitos.

9 Inocêncio Mártires Coelho, "Đireito, Estado e Estado de Direito", Revista de Informação Legislativa, Brasilia, Senado Federal, 1990(108), p. 18.

10 Anderson Cavalcante Lobato, Le système mixte de controle de constitutionnalité: le cas $d u$ Brésil et $d u$ Portugal, Tese de Doutorado, Universidade de Toulouse, fevereiro de 1994 , p. 216.

R. Fac. Direito, Curitiba, a.28, n.28, 1994/95, p. 109-137 
Ainda sob a influência do jusnaturalismo, encontramos a expressão direitos do homem ou direitos humanos, correntemente utilizada nos textos de direito internacional. Agrupando diversas correntes filosóficas de caráter humanista, esta expressão procura ressaltar igualmente a dimensão de universalidade, designando aqueles direitos supra-estatais. Eles permanecem profundamente vinculados à idéia das declarações de direitos e neste sentido, têm um valor jurídico-constitucional reduzido. ${ }^{11}$

Utiliza-se freqüentemente a expressão liberdades públicas para designar aqueles direitos que estão tutelados jurídica e jurisdicionalmente. No entanto, esta expressão traz consigo uma dificuldade quanto à amplitude dos direitos tutelados, identificando-se muitas vezes com a corrente liberal que concede um efetivo valor jurídico somente aos direitos e liberdades individuais e coletivos. $^{12}$

Da mesma forma, quando se quer tratar somente de certa e determinada categoria de direitos utiliza-se expressões tais como: direitos individuais, direitos coletivos, direitos sociais, econômicos e culturais.

A expressão direitos e garantias procura justamente ressaltar o fato de se prever conjuntamente com os direitos, certos mecanismos jurídicos e jurisdicionais que lhes possam dar efetividade e concretização.

Recentemente, sob a influência dos juspublicistas alemães, adotouse a expressão direitos fundamentais para designar aqueles direitos inerentes à pessoa humana, inseridos no texto das constituições e que se encontram portanto, tutelados jurídica e jurisdicionalmente pelo Estado. ${ }^{13}$

A constitucionalização dos direitos do homem garante pois, o seu reconhecimento enquanto direitos fundamentais, juridicamente positivados e protegidos, posto que são suscetíveis de serem discutidos e efetivados perante o judiciário. ${ }^{14}$ No entanto, o processo de sua incorporação constitucional é lento e permanente. E, para melhor compreendê-lo, podemos

11 José Afonso da Silva, Curso de Direito Constitucional Positivo, São Paulo, Malheiros, 1993, p. 162.

c.

12 José Cretella Júnior, Liberdades Públicas, São Paulo, Bushatsky, 1974, p. 45.

13 Paulo Bonavides, Curso de Direito Constitucional, São Paulo, Malheiros, 1993, p. 472.

14 Juan Jose Solozabal Echavarria, "Algunas cuestiones basicas de la teoria de los derechos fundamentales", Revista de Estudios Politicos (nueva epoca), Madrid, 1991(71), p. 97. 
classificar os direitos fundamentais em gerações de direitos, identificandoos historicamente.

\section{B/ As gerações dos direitos fundamentais}

O estudo comparativo das constituições dos Estados contemporâneos nos permite identificar três gerações de direitos no longo processo de incorporação nos textos constitucionais. A primeira geração de direitos situa-se na primeira metade do século XIX e corresponde aos direitos e liberdades de caráter individual, como por exemplo, a liberdade de religião e de consciência, a liberdade de circulação e de expressão, o direito de propriedade e da inviolabilidade do domicílio. A característica comum de todos estes direitos é a de protegerem o indivíduo contra o arbítrio ou abuso do Estado. Podemos citar entre nós a Constituição imperial de 1824, enquanto exemplo deste período de reconhecimento dos direitos individuais e, tendo como exemplo clássico em direito constitucional comparado, a Constituição belga de 1832 .

A segunda geração de direitos fundamentais aparece na segunda metade do século XIX e corresponde ao reconhecimento dos direitos de caráter coletivo, por exemplo, o direito de reunião, de associação, de greve, ou ainda os direitos relativos à participação política do cidadão: o sufrágio universal e o direito de criação dos partidos políticos. Um exemplo entre nós deste período é sem dúvida a primeira Constituição Republicana de 1891 .

Na primeira metade do século XX, começaram a surgir constituições que reconheciam os direitos da terceira geração, que se caracterizam por serem direitos que dependem de uma ação positiva do Estado e estão relacionados às questões de ordem social, econômica e cultural, tais como, o direito ao trabalho, à saúde, à habitação, à educação, ao acesso à cultura e ao lazer.

Nesse momento, obsèrva-se uma mudança importante na concepção do Estado que deixa de ser visto exclusivamente enquanto manifestação de um poder despótico e passa a ser reconhecido enquanto poder capaz de garantir o equilíbrio social e econômico. A sociedade deixa de se preocupar somente com a proteção do indivíduo diante da ação do Estado para, ao contrário, exigir sua ação no sentido da concretização dos novos direitos

R. Fac. Direito, Curitiba, a. 28, n.28, 1994/95, p. 109-137 
econômicos, sociais e culturais. ${ }^{15}$ Podemos citar entre nós o exemplo das constituições de 1934 e de 1946 que são representativas deste período.

A atual Constituição brasileira de 1988 constitui um Estado Democrático de Direito, onde, já dissemos, se percebe uma opção de compromisso entre o Estado liberal e o Estado social de direito. Compromisso este somente possível se baseado no princípio democrático.

Nos referimos, no início, ao processo permanente de reconhecimento de novos direitos do homem que assumem a natureza de direitos fundamentais quando incorporados ao texto constitucional. Trata-se pois, do princípio constitucional da lista aberta dos direitos fundamentais que se encontra expresso no parágrafo $2 .^{\circ}$, do artigo $5^{\circ}$, da Constituição de 1988 , nos seguintes termos: "os direitos e garantias expressos nesta Constituição não excluem outros decorrentes do regime e dos princípios por ela adotados, ou dos tratados internacionais em que a República Federativa do Brasil seja parte". O princípio da lista aberta permite assim o reconhecimento gradual e permanente de novos direitos, decorrentes sobretudo dos tratados e acordos internacionais, nos quais o Estado brasileiro participa. ${ }^{16}$

Deste modo, percebe-se hoje, no final do século XX, o surgimento de uma quarta geração de direitos, correspondente àqueles que se relacionam com o progresso da ciência, como o direito à não manipulação genética, ou ainda aqueles identificados à solidariedade entre os povos, como o direito ao desenvolvimento, ao meio ambiente e ao patrimônio comum da humanidade. Neste sentido, temos notícia do movimento internacional coordenado pela Fundação Cousteau pela adoção pela Assembléia das Nações Unidas dos direitos das futuras gerações, relacionados à proteção ao meio ambiente e ao desenvolvimento social e industrial ecologicamente sustentável. ${ }^{17}$

Ver Henrique Mota, "Le principe de la 'liste ouverte' en matière de droits fondamentaux", in La justice constitucionnelle au Portugal, Paris, Economica, 1989, p. 179.

17 Ronny Hein, "Jacques Cousteau: um mergulho na utopia", in Os Caminhos da Terra, Ed. Azul, abril de 1994, p. 48 e ss. 
Embora tenhamos aqui apresentado, para efeitos didáticos, os direitos fundamentais divididos em várias gerações representativas do seu processo de reconhecimento e constitucionalização, é necessário deixar claro que a dicotomia aparente entre, por um lado, os direitos de primeira e segunda geração, isto é, direitos civis e políticos, que demandariam uma atitude abstencionista por parte do Estado - direitos de natureza negativa -; e, por outro lado, os direitos da terceira geração, ou seja, direitos econômicos, sociais e culturais, que contrariamente, demandariam uma atitude promotora do Estado - direitos de natureza positiva -, esta aparente antinomia pode e deve ser superada pelo reconhecimento da indivisibilidade e interdependência de todos os direitos fundamentais. ${ }^{18}$

Resta-nos agora analisar quais os direitos que assumem a qualidade de direitos fundamentais no contexto brasileiro pela incorporação no texto da Constituição Federal de 1988.

\section{$\mathrm{Cl}$ Os direitos fundamentais reconhecidos pela Constituição Federal de 1988}

Os constituintes de 1987/88 tiveram uma grande preocupação com os direitos fundamentais. Esta preocupação se concentrou particularmente no aspecto de sua efetividade. De fato, somente a incorporação constitucional dos direitos do homem não seria de modo algum suficiente para garantir-lhes aplicação concreta. Porém, o Estado democrático de direito é justamente fruto do compromisso assumido entre as concepções liberalizante e socializante do Estado. É por esta razão que encontramos muitas vezes preceitos constitucionais aparentemente contraditórios entre si ou que deixam sérias dúvidas sobre o seu modo de aplicação. Somente a idéia de compromisso pode explicar e contribuir na interpretação e aplicação concreta destes preceitos e princípios constitucionais. Veremos agora que essas questões constitucionais aparecem com freqüência na enumeração dos direitos fundamentais no tẹxto da Constituição Federal de 1988.

18 A partir de uma perspectiva internacional: Antônio Augusto Cançado Trindade, "A questão da implementação dos direitos econômicos, sociais e culturais: evolução e tendências atuais", Revista Brasileira de Estudos Politicos, UFMG, 1990(71), p. 16 e ss.

R. Fac. Direito, Curitiba, a.28, n.28, 1994/95, p.109-137 
Os direitos fundamentais estão enumerados no Título II da Constituição de 1988, intitulado: "Dos Direitos e Garantias Fundamentais". Este título está dividido em cinco capítulos, com 13 artigos (do art. 5. ao 17). Os direitos individuais e coletivos da primeira e segunda geração de direitos, adquiriram neste final de século uma quase unanimidade de modo que na Constituição compromisso de 1988, eles terminaram ocupando um espaço significativo do Título II. Estão pois distribuídos em quatro capítulos: Capítulo I, "Dos Direitos e Deveres Individuais e Coletivos", com o artigo 5. e seus setenta e sete incisos e dois parágrafos; o Capítulo III, "Da Nacionalidade", com dois artigos (arts. 12 e 13); o Capítulo IV, "Dos Direitos Políticos", artigos de 14 a 16; e o Capítulo V, "Dos Partidos Políticos", com o artigo 17.

Os direitos fundamentais da terceira geração, a saber os direitos sociais, econômicos e culturais, justamente por representarem um ponto essencial de conflito, ficaram restritos à enumeração do Capítulo II, "Dos Direitos Sociais", com os artigos de 6 a 11. Sendo que o artigo $6 .^{\circ}$ se limita à indicação genérica dos direitos sociais, quais sejam: a educação, a saúde, o trabalho, o lazer, a segurança, a previdência social, a proteção à maternidade e à infância, a assistência aos desamparados. Porém, o desenvolvimento desses direitos ficou para o final do texto constitucional, Título VII, "Da Ordem Econômica e Financeira", com quatro capítulos: Capítulo I, "Dos Princípios Gerais da Atividade Econômica" (arts. 170 a 181); Capítulo II, "Da Política Urbana (arts. 182 e 183); Capítulo III, "Da Política Agrícola e Fundiária e da Reforma Agrária" (arts. 184 a 191); Capítulo IV, "Do Sistema Financeiro Nacional (art. 192); bem como o Título VIII, intitulado "Da Ordem Social", com nada menos que oito capítulos: Capítulo I, "Disposições Gerais" (art. 193); Capítulo II, "Da Seguridade Social" (arts. 194 a 204); Capítulo III, "Da Educação, da Cultura e do Desporto" (arts. 205 a 217); Capítulo IV, "Da Ciência e da Tecnologia" (arts. 218 e 219); Capítulo V, "Da Comunicação Social" (arts. 220 a 224); Capítulo VI, "Do Meio Ambiente" (art. 225); Capítulo VII, "Da Família, da Criança, do Adolescente e do Idoso (arts. 226 a 232); Capítulo VIII, "Dos Índios" (arts. 231 e 232).

Ora, do estudo aprofundado dos artigos 7 a 1 do Capítulo II, intitulado "Dos Direitos Sociais", ressalta o fato de tratarem mais precisamente dos direitos individuais e coletivos inerentes ao cidadão trabalhador e que somente de uma forma indireta se lhes pode conceder uma dimensão social. Assim, os direitos fundamentais da terceira geração se concentram pois nos títulos VII e VIII, que cuidam respectivamente da ordem econômica e social. 
Identificados os direitos reconhecidos pela Constituição de 1988 podemos agora analisar os mecanismos de proteção jurídica e jurisdicional garantidos aos cidadãos brasileiros, visando precisamente a obtenção de uma maior eficácia jurídica.

\section{II.- As garantias jurídicas dos direitos fundamentais}

A incorporação dos direitos do homem no texto constitucional, trouxe a preocupação por uma estrutura jurídica-constitucional capaz de garantir por um lado, a imutabilidade dos direitos reconhecidos, e por outro lado, a aplicação concreta desses direitos.

Estes objetivos só poderiam ser alcançados pela afirmação de certas garantias jurídicas tais como a aplicabilidade imediata dos direitos fundamentais (A); a determinação de imutabilidade dos direitos reconhecidos através dos limites impostos ao processo de reforma constitucional (B); e a imposição de limites concretos à possibilidade de restrição de direitos nos momentos de crise constitucional (C).

\section{A/ A garantia de aplicação imediata dos direitos fundamentais}

As constituições contemporâneas costumam garantir aplicação imediata às normas definidoras dos direitos fundamentais. Assim, a Constituição brasileira de 1988 , estabeleceu expressamente no artigo $5 .^{\circ}$, parágrafo $1 .^{\circ}$, que: "as normas definidoras dos direitos e garantias fundamentais têm aplicação imediata". Porém, qual seria o significado concreto da constitucionalização da idéia de aplicação imediata das normas definidoras de direitos, se de fato, as normas constitucionais gozam de imperatividade, ${ }^{19}$ posto que esta seria uma característica de toda norma jurídica? Com maioria de razão, não dẻveriam as normas constitucionais gozarem de

19 Luis Roberto Barroso, O Direito Constitucional e a efetividade de suas normas, $2^{\mathrm{a}}$ edição, at. e ampl., Rio de Janeiro, Renovar, 1993, p. 71.

R. Fac. Direito, Curitiba, a.28, n.28, 1994/95, p.109-137 
maior obrigatoriedade por força do princípio da supremacia constitucional inerente às Constituições rígidas? ${ }^{20}$

Em realidade a necessidade da garantia de aplicação imediata das normas definidoras de direitos fundamentais tem razões históricas. Tivemos a oportunidade de compreender como os direitos inerentes à pessoa humana foram gradativamente adquirindo valor jurídico-constitucional, à medida que eram incorporados ao texto das constituições contemporâneas. Ora, este longo processo não ocorreu sem resiștência, particularmente de ordem doutrinária e jurisprudencial. Com efeito, ainda que inseridos no texto constitucional, surgiram desde logo teses tendentes a lhes atribuir valor jurídico reduzido, destituindo-os de obrigatoriedade.

Identificamos primeiramente junto à jurisprudência norte-americana, a distinção entre (a) normas constitucionais mandatórias, mandatory provisions, de caráter obrigatório; e (b) normas constitucionais diretórias, directory provisions, desprovidas de obrigatoriedade, não vinculando nem a atuação do poder público, nem dos particulares. ${ }^{21}$

Do mesmo modo, foi entre os norte-americanos que surgiu a classificação das normas constitucionais quanto à aplicabilidade em (a) normas auto-aplicáveis, self-executing, que seriam desde logo aplicáveis, porque estariam diretamente regulamentando as situações fáticas a que se referem; e (b) normas não auto-aplicáveis, not self-executing, que não poderiam ser imediatamente aplicadas porque dependeriam de norma infraconstitucional regulamentadora que lhes garantisse aplicabilidade. ${ }^{22}$

Embora considerada superada e incompatível com a realidade das constituições contemporâneas, ${ }^{23}$ fato é que esta classificação vem sendo seguidamente utilizada por nossos tribunais para afastar a aplicação de certas normas constitucionais considerando-as pois dependentes de regulamentação infraconstitucional.

Maria Helena Diniz, Norma constitucional e seus efcitos, $2^{a}$ edição, São Paulo, Saraiva, 1992 , p. 13 ss.

21 Luis Roberto Barroso, O Direito..., op. cit., p. 72.

22 José Afonso da Silva, Aplicabilidade das normas constitucionais, São Paulo, Ed. Revista dos Tribunais, 1982, p. 64.

23 José Afonso da Silva, Aplicabilidade..., op. cit., p. 66. 
O professor José Afonso da Silva, nos dá notícia ainda da classificação elaborada pela jurisprudência italiana que considerou a existência de normas constitucionais destituídas de natureza jurídica, denominadas programáticas, e que se aproximariam das declarações de direito sem que houvesse garantia jurídica e jurisdicional possível de lhes atribuir um mínimo de imperatividade. ${ }^{24}$

É preciso primeiramente situar corretamente o conceito de aplicabilidade das normas constitucionais. Assim, se para o cientista político, a idéia de aplicabilidade está ligada a sua efetividade, ou seja, ao fato de que a norma esteja sendo devidamente cumprida e observada, para o jurista, "a aplicabilidade das normas constitucionais (também de outras) depende especialmente de saber se estão vigentes, se são legítimas, se têm eficácia". ${ }^{25}$

De modo que, a expressa afirmação da aplicação imediata das normas constitucionais definidoras dos direitos fundamentais busca lhes garantir uma maior efetividade.

Os constituintes brasileiros de 1987/88 procuraram garantir aplicação imediata às normas definidoras dos direitos fundamentais enumerados no Título II, que se apresentam enquanto normas auto-aplicáveis, posto que não necessitam de norma regulamentadora infraconstitucional.

É verdade que, a grande maioria das normas constitucionais inseridas nos Títulos VII e VIII da Constituição e que procuram dar um maior desenvolvimento aos direitos sociais, econômicos e culturais, se apresentam enquanto normas não auto-aplicáveis, necessitando pois de regulamentação infraconstitucional para serem efetivadas. No entanto, é preciso deixar claro que enquanto normas jurídicas de valor constitucional, produzem efeitos jurídicos imediatos, tais como a revogação e a caracterização da inconstitucionalidade de toda legislação infraconstitucional incompatível com os novos direitos, ou ainda abrindo a possibilidade do exercício das novas garantias jurisdicionais expressas pelo mandado de injunção e pela ação de inconstitucicnalidade por omissão, temas que teremos a ocasião de abordar ainda neste estudo.

24 José Afonso da Silva, Aplicabilidade..., op. cit., p. 69.

25 José Afonso da Silva, Aplicabilidade..., op. cit., p. 42.

R. Fac. Direito, Curitiba, a.28, n.28, 1994/95, p.109-137 


\section{B/ Os limites materiais impostos ao processo de reforma constitucional}

O processo de reforma das constituições rígidas deve respeitar certas condições ou limites que podem assumir uma natureza formal, quando tratam do processo constituinte, ou uma natureza material, quando procuram impedir a modificação de regras e princípios considerados essenciais à identidade do Estado.

A Constituição brasileira de 1988 prevê ordinariamente um único processo de reforma constitucional: a emenda à Constituição (art. 60, CRFB). De fato, o processo de revisão constitucional previsto no artigo $3 .^{\circ}$ do Ato das Disposições Constitucionais Transitórias foi sem dúvida excepcional, e se encontra encerrado.

$\mathrm{O}$ artigo 60 da Constituição começa estabelecendo os limites de natureza formal que conduzem o processo de emenda constitucional, a saber: a iniciativa (art. 60, I, II e III); a discussão e quorum de votação (art. $60, \S 2 .^{\circ}$ ); e a promulgação (art. $60, \S 3 .^{\circ}$ ). Em seguida, no $\S 4 .^{\circ}$, aparecem os limites materiais, proibindo a proposição de emenda objetivando abolir: (I) a forma federativa de Estado; (II) o voto direto, secreto, universal e periódico; (III) a separação de poderes; e (IV) os direitos e garantias individuais.

Prevaleceu aqui a concepção liberal dos direitos fundamentais, posto que se concedeu o caráter permanente e imutável somente aos direitos individuais da primeira geração. Os direitos coletivos, sociais, econômicos e culturais, da segunda e terceira geração de direitos e que estão inseridos especialmente no Capítulo II, do Título II, e são desenvolvidos detalhadamente nos Títulos VII e VIII da Constituição, foram considerados, por via de consequência, conjunturais, admitindo-se pois, modificação através de emenda constitucional.

\section{C/ As restrições impostas à décretação do estado de exceção constitucional}

O Estado constitucional deve regulamentar igualmente os momentos de crise institucional que exijam a adoção de medidas excepcionais. Os Estados latino-americanos guardam um grande receio, muitas vezes justi- 
ficado, de que a crise se prolongue indefinidamente, transformando o Estado constitucional em Estado autoritário. Deste modo, se faz necessário estabelecer mecanismos de controle político e jurídico, das medidas excepcionais adotadas em momentos de crise do Estado.

A Constituição de 1988 procurou resguardar os direitos fundamentais das medidas tomadas em estado de exceção constitucional. Indicou-se taxativamente quais direitos fundamentais seriam suscetíveis de limitação pelo decreto presidencial de exceção. Com efeito, são duas as medidas que podem ser tomadas na defesa do estado e das instituições democráticas, o estado de defesa e o estado de sítio.

O estado de defesa pode ser decretado pelo Presidente da República, após consulta do Conselho da República e do Conselho de Defesa Nacional, para preservar ou restabelecer a ordem pública ou a paz social ameaçadas por grave e iminente instabilidade institucional ou atingidas por calamidades. Deve ser decretado por prazo de 30 dias, prorrogável uma única vez pelo mesmo período. O controle político será exercido pelo Congresso Nacional que receberá a comunicação do ato, com a sua respectiva justificativa, no prazo de 24 horas, podendo rejeitá-lo pelo quorum da maioria absoluta, caso em que cessará imediatamente o estado de defesa.

Quanto à proteção dos direitos fundamentais, ficou expresso no artigo $136, \S 1 .^{\circ}$, inc. I, que as medidas tomadas no estado de defesa só poderão restringir certos e determinados direitos, quais sejam: o direito de reunião, ainda que exercida no seio das associações; e, o sigilo da correspondência, das comunicações telegráficas e telefônicas.

O estado de sítio pode ser decretado pelo Presidente da República, mediante consulta ao Conselho da República e ao Conselho de Defesa Nacional, havendo ainda necessidade de uma autorização prévia do Congresso Nacional, que exercerá assim um controle político do ato. As hipóteses são as seguintes: (a) grave comoção de repercussão nacional ou comprovação de ineficácia das medidas tomadas no estado de defesa; e, (b) declaração de guerra ou resposta a agressão armada estrangeira. $\mathrm{Na}$ primeira hipótese, o decreto terá uma duração de 30 dias, prorrogável por igual período, quantas vezes for necessário. Já na segunda hipótese, o decreto vigorará enquanto perdurar o conflito armado, sendo que a proteção dos direitos fundamentais ficará assegurada pela exigência do artigo 138, afirmando que o próprio decreto deverá indicar as garantias constitucionais

R. Fac. Direito, Curitiba, a.28, n.28, 1994/95, p.109-137 
que ficarão restringidas ou suspensas, de modo a permitir um controle político e jurisdicional futuro.

Nos incisos de I a VII, do artigo 139, estão indicados os direitos fundamentais que poderão ser restringidos quando da decretação do estado de sítio com fundamento na primeira hipótese prevista no art. 137, inc. I, da Constituição, sendo possível restringir-se além dos direitos indicados para o caso de decretação do estado de defesa, os seguintes direitos fundamentais: (a) o direito de locomoção, com possibilidade de detenção em edifícios não destinados a acusados ou condenados por crimes comuns; (b) a liberdade de imprensa, radiodifusão e televisão; (c) o direito de inviolabilidade do domicílio; (d) o direito de propriedade, pela possibilidade de intervenção nas empresas de serviços públicos e admitindo-se a requisição de bens.

A indicação exaustiva dos direitos fundamentais suscetíveis de serem restringidos no estado de crise institucional com a decretação do estado de defesa ou do estado de sítio, representa sem dúvida uma garantia jurídica de proteção desses direitos. Esta opção dos constituintes permitirá o exercício do controle jurisdicional da conformidade à Constituição do ato presidencial de instauração do estado de exceção, uma vez restabelecida a normalidade constitucional.

\section{III.- As garantias jurisdicionais: as ações constitucionais de proteção dos direitos fundamentais}

A incorporação dos direitos do homem no texto constitucional thes permite uma proteção jurisdicional através da aplicação do princípio da supremacia da Constituição, e conseqüentemente, do sistema de controle jurisdicional da constitucionalidade das leis e dos atos normativos.

A Constituição brasileira de 1988 consolidou a tendência pela adoção, no Brasil, de um sistema misto de cortrole de constitucionalidade, onde se procura conjugar o sistema difuso e concentrado de controle, ou seja, onde a questão de inconstitucionalidade pode ser suscitada perante todo juiz e tribunal visando a solução de um caso concreto ou ainda, por certas e determinadas autoridades perante o Supremo Tribunal Federal, pela 
via do controle abstrato das normas, independentemente da existência de um caso concreto.

A jurisdição constitucional no Brasil permite pois que as questões de inconstitucionalidade - e aqui se pode incluir a violação de um direito fundamental - possam ser imediatamente suscitadas e decididas perante qualquer juiz ou tribunal. Contudo, a proteção dos direitos fundamentais exige muitas vezes um procedimento mais célere para garantir a efetividade da decisão, desse modo, percebemos pouco a pouco o crescimento da demanda por ações constitucionais que visem especificamente oferecer uma proteção jurisdicional aos direitos fundamentais expressos na Constituição.

A expressão jurisdição constitucional das liberdades adotada pelo jurista italiano Mauro Cappelletti, visa justamente designar a existência de um processo constitucional especial para a proteção dos direitos fundamentais. ${ }^{26}$ Desperta grande interesse a problemática do acesso direto dos cidadãos à ações de natureża constitucional que possam imediatamente garantir efetividade aos direitos fundamentais.

Os países europeus de jurisdição concentrada conhecem dois exemplos que não podemos deixar de mencionar: o recurso constitucional alemão e o recurso de amparo espanhol. Ambos visam permitir a todo cidadão que se sinta lesado em seus direitos fundamentais, de encaminhar a questão ao Tribunal Constitucional.

No que diz respeito ao recurso constitucional alemão (verfassungsbeschwerde) é importante perceber que teoricamente se assemelha ao mandado de segurança brasileiro, em razão sobretudo da possibilidade de sua apresentação por qualquer pessoa que se sinta lesada em um de seus direitos fundamentais por ato de autoridade pública (art. 93-4a, Constituição Federal Alemã). Entretanto, na prática, o recurso constitucional se aproxima do nosso recurso extraordinário, posto que o art. 94-2, da Constituição de Bonn, admite que uma lei federal possa restringir o acesso direto do interessado à tentativa de solução do caso pela via do direito ordinário. Deste modo, "a atividade do Tribunal Constitucional Federal no plano do

R. Fac. Direito, Curitiba, a.28, n.28, 1994/95, p. 109-137 
recurso constitucional se limita quase inteiramente à verificação da constitucionalidade das decisões de justiça". ${ }^{27}$

O recurso de amparo espanhol foi concebido a partir do modelo do recurso constitucional alemão, e apesar de certas e determinadas particularidades, ${ }^{28}$ nos é permitido concluir, que guarda a mesma estrutura jurídica de modo a ressaltar uma semelhança e proximidade com os institutos do mandado de segurança e recurso extraordinário brasileiros. ${ }^{29}$

Os constituintes brasileiros de 1987/88, preocupados com o acesso direto dos cidadãos à justiça constitucional, idealizaram um recurso especial qual seja: a argüição de descumprimento de preceito fundamental decorrente da Constituição, previsto no parágrafo $1 .^{\circ}$, do artigo 102 da Constituição Federal. A utilização deste novo recurso está diferida por falta de regulamentação infraconstitucional. Porém, ele representa de fato uma maior concentração das questões constitucionais envolvendo os direitos fundamentais.

A verdade é que a jurisdição constitucional brasileira, tradicionalmente difusa, já prevê a existência de ações constitucionais que procuram dar solução imediata quando ocorra violação de certos direitos fundamentais. São as ações constitucionais, de natureza mandamental e de rito especial, que estão previstas no artigo $5 .^{\circ}$ da Constituição de 1988.

O estudo do processo de reconhecimento dos direitos fundamentais nos permite identificar dois blocos de ações constitucionais segundo os direitos protegidos, num primeiro bloco encontramos as ações constitucionais destinadas à proteção dos direitos individuais e coletivos (A), e no

27 Dietrich Katzenstein, "Rapport Allemand. Partie I: L'accèes direct à la protection: techniues et résultats". III ${ }^{\mathrm{e}}$ Colloque International d'Aix-en-Provence: Cours Constitucionnelles Européennes et droits fondamentaux, in Annuaire International de Justice Constitutionnelle, Paris/Aix-en-Provence, Economica/PUAM, 1991-VII, 1993, p. 97.

28 Francisco Rubio Llorente, "Rapport Espagnol. Partie I: L'accès direct à la protection: techniques et résultats", III ${ }^{\mathrm{e}}$ Colloque International d'Aix-en-Provence: Cours Constitucionnelles Européennes et droits fondamentaux, in Annuaire International de Justice Constitutionnelle, Paris/Aix-en-Provence, Economica/PUAM, 1991-VII, 1993, p. $133 / 4$.

29 Anderson Cavalcante Lobato, Le système mixte..., op. cit., p. 301 e ss. 
segundo bloco, as ações constitucionais de proteção dos direitos sociais, econômicos e culturais (B).

\section{Al As ações constitucionais de proteção dos direitos individuais e coletivos}

A primeira ação constitucional reconhecida pelo constitucionalismo brasileiro foi a ação de habeas corpus visando a proteção da liberdade de locomoção. É verdade que os primeiros anos da República, com a adoção da Constituição de 1891 , possibilitou o desenvolvimento da doutrina brasileira do habeas corpus, quando se procurava admitir o presente instituto enquanto mecanismo jurisdicional de defesa do cidadão contra todo e qualquer ato do poder público eivado de ilegalidade ou abuso do poder. Tratava-se de uma ampliação sem precedentes da ação de habeas corpus, com o objetivo de proteger todo e qualquer direito individual em face do arbítrio da administração.

A Constituição brasileira de 1934, buscando inspiração na doutrina brasileira do habeas corpus e por influência do recurso de amparo mexicano, instituiu a ação constitucional do mandado de segurança, visando a proteção de todo e qualquer direito líquido e certo não amparado pelo habeas corpus. O maior problema na conceituação do novo instrumento constitucional residia justamente na correta compreensão da expressão "direito líquido e certo". A discussão na doutrina e nos tribunais a respeito do seu significado foi extremamente rica, tendo-se chegado a conclusão de que a sua compreensão não pode estar dissociada do procedimento especial e sumário previsto na ação constitucional, de modo que por "direito líquido e certo" há que se entender todo aquele direito passível de ser demonstrado direta e imediatamente sem necessidade de maior dilação probatória.

Quando comparamos, ainda que rapidamente, a ação de mandado de segurança com o recurso constitucional alemão ou com o recurso de amparo espanhol, percebemos que além da particular diferença de jurisdição difusa, no caso brasileiro, e concentrada, no modelo europeu, existiria uma diferença significativa dos direitos protegidos, posto que no exemplo europeu, a proteção se limita aos direitos fundamentais da primeira e da segunda geração, cuja preocupação básica está na proteção do indivíduo contra 0 arbítrio do Estado. Deste modo, a ação constitucional deverá demonstrar

R. Fac. Direito, Curitiba, a.28, n.28, 1994/95, p. 109-137 
claramente a violação de um direito reconhecido pelo texto constitucional. ${ }^{30}$ Ora, no caso da ação de mandado de segurança, o autor deverá tão somente demonstrar a violação de um direito que se apresente de forma clara e objetiva, portanto líquido e certo, não havendo pois necessidade de uma referência direta ao texto constitucional. Assim sendo, a proteção jurisdicional concedida pelo mandado de segurança brasileiro alcança uma maior amplitude posto que permite um controle da constitucionalidade e da legalidade dos atos de autoridade pública. Certo é que esta amplitude se justifica sobretudo em razão da inexistência entre nós do contencioso administrativo que exerce, nos países europeus, o controle da legalidade dos atos da administração pública. Se compreenderia assim a importância adquirida pela ação de mandado de segurança na realidade jurídica e jurisdicional brasileira.

A Constituição brasileira de 1988 enriqueceu sobremaneira as ações constitucionais de proteção dos direitos individuais e coletivos, reconhecendo primeiramente a ação de habeas corpus (art. $5^{\circ}$, LXVIII, CF), visando exclusivamente a proteção da liberdade de locomoção e a ação de mandado de segurança individual (art. 5. ${ }^{\circ}$, LXIX, CF), visando a proteção dos outros direitos individuais. A novidade trazida está na dimensão coletiva do mandado de segurança (art. $5^{\circ}, \mathrm{LXX}, \mathrm{CF}$ ), permitindo a sua utilização pelos partidos políticos, organização sindical, entidade de classe ou associação, sempre em defesa dos interesses coletivos que representam.

O constituinte entendeu necessária a introdução da ação de habeas data (art. 5. ${ }^{\circ}, \mathrm{LXXII}, \mathrm{CF}$ ), visando garantir o acesso e, se necessário, a correção, das informações sobre a pessoa do demandante, inseridas em registros ou bancos de dados de entidades governamentais ou de caráter público. É verdade que a recusa em fornecer tais informações poderia caracterizar a violação de um direito líquido e certo passível de correção pela via do mandado de segurança, entretanto, tendo em vista a experiência recente do período autoritário conjugada com a proliferação de bancos de dados informatizados de fácil criação e utilização, se justificaria assim a adoção de uma ação constitucional específica que, assumindo o rito especial e sumário próprio das ações constitucionais de proteção dos direitos funda- 
mentais, podedo assim garantir melhor o direito individual de informação e da privacidade.

As ações constitucionais até então enumeradas têm um eixo comum porque têm como finalidade a proteção de direitos individuais e coletivos, da primeira e segunda geração dos direitos fundamentais. São ações dirigidas contra o Estado que, por ilegalidade ou abuso de poder, viola ou deixa de reconhecer o direito do demandante. Em razão do profundo enraizamento destes direitos e garantias na cultura ocidental, pode-se obter aqui um maior grau de efetividade. O mesmo não acontece com os direitos sociais, econômicos e culturais da terceira geração dos direitos fundamentais, cujo reconhecimento é ainda recente, suscitando assim uma grande dificuldade de aplicação concreta.

\section{B/ As ações constitucionais de proteção dos direitos sociais, econômicos e culturais}

A primeira e importante característica dos direitos sociais, econômicos e culturais da terceira geração dos direitos fundamentais está em exigir uma ação positiva do Estado para a sua concretização. Tal exigência, motivou a aceitação de um novo tipo de inconstitucionalidade, a saber, a inconstitucionalidade por omissão, resultante da inércia ou do silêncio prolongado dos órgãos públicos, pela falta de medidas legislativas, de governo ou mesmo de natureza administrativa. ${ }^{31}$

Por influência da Constituição portuguesa de 1976, o constituinte brasileiro de 1987/88 introduziu a inconstitucionalidade por omissão dentre as possibilidades de verificação abstrata da constitucionalidade das normas através da Ação direta de inconstitucionalidade (art. 103, § 2., $\mathrm{CF}$ ). Entretanto, a novidade, sem precedentes, trazida pela Constituição de 1988, está na criação da ação de mandado de injunção (art. $5 .^{\circ}, \mathrm{LXXI}, \mathrm{CF}$ ), visando garantir a aplicação imediata dos direitos e liberdades constitucionais, bem

31 Jorge Miranda, Manual de Direito Constitucional, Tomo II: "Constituição e Inconstitucionalidade", Coimbra, Coimbra Editora, 1991, p. 338; Flávia Piovesan, Proteção judicial contra omissões legislativas, São Paulo, Ed. Revista dos Tribunais, 1995 , p. 78.

R. Fac. Direito, Curitiba, a.28, n.28, 1994/95, p.109-137 
como das prerrogativas inerentes à nacionalidade, à soberania e à cidadania, sempre que a inércia do poder público inviabilizar ou dificultar o seu pleno exercício. ${ }^{32}$

A primeira leitura do novo instrumento de garantia constitucional dos direitos fundamentais limitava-o à defesa dos direitos de primeira e segunda geração, inseridos no Título II da Constituição de 1988 (arts. 5. ${ }^{\circ}$ a 17). Ora, uma interpretação teleológica e sistêmica não pode deixar de compreender a ação de mandado de injunção enquanto um instrumento de defesa do indivíduo frente a inércia do Estado em promover os direitos fundamentais da terceira geração, ou seja, os direitos sociais, econômicos e culturais. Na Constituição brasileira de 1988, tais direitos foram desenvolvidos nos Títulos VII e VIII, tratando respectivamente dos direitos econômicos e sociais.

Há que considerar-se por um lado, o fato de que o constituinte, na busca do compromisso, utilizou-se freqüentemente de normas de eficácia limitada, deixando para o embate político futuro a tarefa de concretização dos direitos constitucionais, através de norma infraconstitucional regulamentadora. Deste modo, poder-se-ia admitir a utilização da ação de mandado de injunção para garantir qualquer outro direito inserido na Constituição de 1988 mesmo que fora dos títulos acima mencionados destinados à definição e reconhecimento expresso dos direitos fundamentais. Por outro lado, a norma definidora do mandado de injunção refere-se primeiramente a "direitos e liberdades constitucionais", não permitindo assim uma interpretação restritiva, admitindo a ação somente para garantir certos e determinados direitos fundamentais. ${ }^{33}$

No entanto a maior dificuldade que tem encontrado doutrinadores e tribunais no tratamento jurídico-constitucional da ação de mandado de injunção está na definição de seus efeitos jurídicos. O Supremo Tribunal

32 José Rubens Costa, "O mandado de injunção como norma garantidora dos direitos sociais", in Mandados de segurança e de injunção, Coord. de Sálvio de Figueiredo Teixeira, São Paulo, Saraiva, 1990, p. 432.

33 Carlos Mário da Silva Velloso, "A nova feição do mandado de injunção", Revista de Direito Público, 1991(100), p. 170; José Afonso da Silva, "Mandado de Injunção", in Mandados de segurança e de injunção, Coord. de Sálvio de Figueiredo Teixeira, São Paulo, Saraiva, 1990, p. 399; Flávia Piovesan, Proteção judicial..., op. cit., p. 123; 
Federal entendeu correto equiparar os efeitos jurídicos da decisão na ação de mandado de injunção aos efeitos produzidos pela declaração de inconstitucionalidade por omissão. ${ }^{34}$ Assim procedendo, deixou obscurecida a diferença fundamental entre ambos institutos jurisdicionais. De fato, a ação de inconstitucionalidade por omissão tem como objetivo principal a proteção da ordem jurídica-constitucional; a ação de mandado de injunção, por sua vez, tem a finalidade de garantir o exercício de um direito fundamental inibido pela falta de norma regulamentadora.

Entretanto, recentemente, percebe-se pouco a pouco uma mudança de orientação da parte do Supremo Tribunal Federal, no sentido de admitir efeitos imediatos e concretos à decisão que reconhece a omissão inconstitucional nos processos de injunção. ${ }^{35}$

É verdade que a mudança jurisprudencial se limita a conceder aplicabilidade imediata à norma constitucional não auto-aplicável, sem que houvesse necessidade do pronunciamento de uma sentença normativa ou integrativa do direito. Porém, em assim procedendo, o judiciário já está caminhando no sentido da proteção do direito fundamental, pela sua realização ou efetividade, independentemente da inércia do poder público. ${ }^{36}$

A segunda característica dos direitos sociais, econômicos e culturais da terceira geração dos direitos fundamentais, reside na sua manifestação enquanto interesses difusos, identificados pela pluralidade de sujeitos e indivisibilidade de seu objeto, de modo que não se possa determinar um ou alguns sujeitos com a exclusão dos demais, como por exemplo, o direito à proteção do meio ambiente, do patrimônio histórico e cultural, ou ainda dos consumidores ${ }^{37}$. Deste modo, "transita-se, portanto, de uma idéia do indivíduo, singularmente concebido, primeiro sujeito ao qual se atribuíram

34 José Carlos Moreira Alves, "A evolução do controle da constitucionalidade no Brasil", in As garantias do cidadão na justiça, Coord. Sálvio de Figueiredo Teixeira, Saraiva, São Paulo, 1993, p. 12.

35 Luis Roberto Barroso, $O$ direito constitucional..., op. cit., p. 183.

36 José Joaquim Gomes Canotilho, "Tomemos a sério o silêncio dos poderes públicos. O direito à emanação de nornłas jurídicas e a proteção judicial contra as omissões normativas", in As garantias do cidadão na Justiça, Coord. Sálvio de Figueiredo Teixeira, São Paulo, Saravia, 1993, p. 364.

37 Hugo Nigro Mazzilli, $A$ defesa dos interesses difusos em juizo, São Paulo, Ed. Revista dos Tribunais, 1994 , p. 21.

R. Fac. Direito, Curitiba, a.28, n.28, 1994/95, p.109-137 
direitos, à idéia de ente coletivo, que transcendem o indivíduo, como novos personagens e novos sujeitos de direitos". ${ }^{38}$

Uma primeira tentativa de proteção desta nova dimensão dos direitos fundamentais pode ser obtida através da Ação Popular, ${ }^{39}$ (art. 5. ${ }^{\circ}$, LXXIII, $\mathrm{CF}$ ), aberta a qualquer cidadão, visando anular todo ato lesivo: (a) ao patrimônio público ou de entidade de que o Estado participe; (b) à moralidade administrativa; (c) ao meio ambiente; e (d) ao patrimônio histórico e cultural.

No entanto, a finalidade da ação popular é sobretudo de controle da atuação governamental e, nesse sentido, a proteção dos direitos difusos aqui alcançada será quase sempre reflexa e limitada pelos contornos processuais da demanda popular. ${ }^{40}$ Deste modo, no Brasil, antes mesmo da Constituição de 1988, foi promulgada a Lei 7.347/85, disciplinando a Ação Civil Pública de responsabilidade por danos causados ao meio ambiente, ao consumidor, a bens e direitos de valor artístico, estético, histórico, turístico e paisagístico. ${ }^{41} \mathrm{O}$ estudo comparativo destes instrumentos processuais revelaria um certo grau de complementariedade entre ambos, como por exemplo, em relação à legitimação ativa, o autor, na ação popular, deve ser sempre o cidadão brasileiro no exercício de um direito político, ao passo que, na ação civil pública, o seu autor poderá ser o Ministério Público, os entes federativos, as autarquias, empresa pública, fundação, sociedade de economia mista ou ainda associação, constituída há pelo menos um ano e que inclua dentre as suas finalidades, tutelar os direitos difusos objeto da demanda (Lei $7.347 / 85$, art. $\left.5 .^{\circ}\right)$.

Em definitivo, estando os direitos fundamentais inseridos no texto constitucional, a sua tutela jurídica e jurisdicional depende diretamente do respeito ao princípio da supremacia constitucional. A jurisdição consti-

38 Flávia Piovesan, "A atual dimensão dos direitos difusos na Constituição de 1988, Revista da Procuradoria Geral do Estado de São Paulo, 1992(38), p. 79.

39 Luís Filipe Colaço Antunes, "Para uma tutela jurisdicional dos interesses difusos", Boletim da Faculdade de Direito, Coimbra, vol. LX, 1984 , p. 211.

40 Elival da Silva Ramos, Ação popular como instumento de participação política, São Paulo, Ed. Revista dos Tribunais, 1991, p. 228.

41 Ver Rodolfo de Camargo Mancuso, Ação civil pública, São Paulo, Ed. Revista dos Tribunais, 1994. 
tucional permite, pois, que cada cidadão suscite uma exceção de inconstitucionalidade, sempre que entender que houve violação de um direito fundamental, constitucionalmente reconhecido e protegido. E, quando há violação do direito por parte do poder público, são colocadas ao alcance de todos, as ações constitucionais, de natureza mandamental e rito sumário, não permitindo-se que a ilegalidade, abuso de poder ou inércia da administração se perpetue. Já quando se tratar de direitos que não possam ser individualizados, assumindo assim a característica de verdadeiros direitos difusos, encontramos de imediato, a ação civil pública e de forma complementar, a ação popular, permitindo-se assim, que o cidadão ou a sociedade civil organizada, possa provocar o judiciário na defesa dos direitos sociais, econômicos e culturais, que favorecem de fato toda a coletividade.

\section{Referências Bibliográficas}

ALVES, José Carlos Moreira. "A evolução do controle da constitucionalidade no Brasil". in As garantias do cidadão na justiça. Coord. Sálvio de Figueiredo Teixeira. São Paulo: Saraiva. 1993, p. 1-14.

ANTUNES, Luís Filipe Colaço. "Para uma tutela jurisdicional dos interesses difusos". Boletim da Faculdade de Direito. Coimbra. vol. LX. 1984, p. 191-221.

BARROSO, Luis Roberto. O Direito Constitucional e a efetividade de suas normas. $2^{\mathrm{a}}$ edição, at. e ampl.. Rio de Janeiro: Renovar, 1993, 429p.

BOBBIO, Norberto. A era dos direitos. Tradução de Carlos Nelson Coutinho. Rio de Janeiro: Editora Campus, 1992, 217p.

BON, Pierre e outros. La justice constitucionnelle au Portugal. Paris: Economica, 1989, $418 \mathrm{p}$.

BONAVIDES, Paulo. Do Estado Liberal ao Estado Social. Belo Horizonte: Del Rey, 1993, 239 p.

BURDEAU, Georges. L'État. Paris: Seuil, 1970, 190p.

CANOTILHO, José Joaquim Gomes. "Tomemos a sério o silêncio dos poderes públicos. O direito à emanação de normas jurídicas e a protecção judicial contra as omissões normativas". in As garantias do cidadão na Justiça. Coord. Sálvio de Figueiredo Teixeira. São Paulo: Saravia. 1993, p. 351-367.

CAPPELLETTI, Mauro. La giurisułzione costituzionale delle libertà. Milano: Giufrrè, 1955.

CHEVALLIER, Jacques. "L'État de droit". Revue du Droit Public et de la Science Politique en France et à l'étranger. Paris: LGDJ. 1988, p. 313-380.

COELHO, Inocêncio Mártires. "Direito, Estado e Estado de Direito". Revista de Informação Legislativa. Brasília: Senado Federal. 1990(108), p. 5-24.

R. Fac. Direito, Curitiba, a.28, n.28, 1994/95, p.109-137 
COSTA, Alvaro Augusto Ribeiro. "Anotações sobre a atual situação dos direitos humanos no Brasil". Arquivo do Ministério da Justiça. Brasilia. 1993(182), p. 137-161.

COSTA, José Rubens. "O mandado de injunção como norma garantidora dos direitos sociais". in Mandados de segurança e de injunção. Coord. de Sálvio de Figueiredo Teixeira. São Paulo: Saraiva. 1990, p. 431-447.

CRETElLA Júnior, José. Liberdades Públicas. São Paulo: Bushatsky, 1974, 241 p.

DALLARI, Dalmo de Abreu. Elementos de Teoria Geral do Estado. São Paulo: Saraiva, $1985,268 \mathrm{p}$.

DESWARTE, Marie-Pauline. "Droits sociaux et État de droit." Revue du Droit Public et de la Science Politique en France et à l'étranger. Paris: LGDJ. 1995(4), p. 951-985.

DINIZ, Maria Helena. Norma constitucional e seus efeitos. $2^{\mathrm{a}}$ edição, atualizada. São Paulo: Saraiva, 1992, 155p.

ECHAVARRIA, Juan Jose Solozabal. "Algunas cuestiones basicas de la teoria de los derechos fundamentales". Revista de Estudios Politicos (nueva epoca). Madrid. 1991(71), p. 87-109.

KATZENSTEIN, Dietrich. "Rapport Allemand. Partie I: L'accèes direct à la protection: techniues et résultats". III ${ }^{\dot{e}}$ Colloque International d'Aix-en-Provence: Cours Constitucionnelles Européennes et droits fondamentaux. in Annuaire International de Justice Constitutionnelle. Paris/Aix-en-Provence: Economica/PUAM. 1991-VII. 1993, p. 89100 .

LLORENTE, Francisco Rubio. "Rapport Espagnol. Partie I: L'accès direct à la protection: techniques et résultats". III ${ }^{\mathrm{e}}$ Colloque International d'Aix-en-Provence: Cours Constitucionnelles Européennes et droits fondamentaux. in Annuaire International de Justice Constitutionnelle. Paris/Aix-en-Provence: Economica/PUAM. 1991-VII. 1993. p. 133140.

LOBATO, Anders on Cavalcante. Le système mixte de controle de constitutionnalite: le cas du Brésil et du Portugal. Tese de Doutorado. Universidade de Toulouse. Fevereiro de $1994,441 \mathrm{p}$.

MAGALHÃES, José Luiz Quadros de. "Direitos humanos: evolução histórica". Revista Brasileira de Estudos Politicos. UFMG. 1992(74/75), p. 91-121.

MANCUSO, Rodolfo de Camargo. Ação civil pública. São Paulo: Ed. Revista dos Tribunais, 1994, 280p.

MAZZILli, Hugo Nigro. A defesa dos interesses difusos em juizo. $6^{\mathrm{a}}$ ed., rev. e atualizada. São Paulo: Ed. Revista dos Tribunais, 1994, 407p.

MIRANDA, Jorge. Manual de Direito Constitucional. Tomo II: "Constituição e Inconstitucionalidade". Coimbra: Coimbra Editora, 1991, 546p.

PIOVESAN, Flávia. Proteção judicial contra omissões législativas. São Paulo: Ed. Revista dos Tribunais, 1995, 191p.

. "A atual dimensão dos direitos difusos na Constituição de 1988. Revista da Procuradoria Geral do Estado de São Paulo. 1992(38), p. 76-88.

RAMOS, Elival da Silva. Ação popular como instumento de participação politica. São Paulo: Ed. Revista dos Tribunais, 1991, 264p. 
REDOR, Marie-Joèlle. De l'État légal à l'État de droit. L'évolution des conceptions de la doctrine publiciste française (1879-1914). Paris: Economica/PUAM, 1992, 389p.

SILVA, José Afonso da. Curso de Direito Constitucional Positivo. São Paulo: Malheiros, 1993, 766p.

"Mandado de Injunção". in Mandados de segurança e de injunção, Coord. de Sálvio de Figueiredo Teixeira. São Paulo: Saraiva. 1990, p. 397-403.

. "O Estado Democrático de Direito". Revista dos Tribunais. São Paulo: Ed. Revista dos Tribunais. 1988(635), p. 7-13.

TRINDADE, Antônio Augusto Cançado. "A questão da implementação dos direitos econômicos, sociais e culturais: evolução e tendências atuais". Revista Brasileira de Estudos Politicos. UFMG. 1990(71), p. 7-55.

VELLOSO, Carlos Mário da Silva. "As novas garantias constitucionais". Revista de Direito Administrativo. Rio de Janeiro: Renovar. 1989(177), p. 14-28.

VELloso, Carlos Mário da Silva. "A nova feição do mandado de injunção". Revista de Direito Público. 1991(100), p. 169-174.

R. Fac. Direito, Curitiba, a. 28, n.28, 1994/95, p. 109-137 